* Service de Pneumologie, Centre des Maladies Orphelines Pulmonaires, Hôpital Cardiovasculaire et Pneumologique Louis Pradel, Université Claude Bernard and Unité Mixte de Recherche 754, "Service de Neurologie A, and "Service de Neurochirurgie A, Hôpital Pierre Wertheimer, Lyon, France. ${ }^{+}$Service de Pneumologie, Hôpitaux Universitaires de Genève, Geneva, Switzerland.

\section{References}

1. Moss J, DeCastro R, Patronas NJ, Taveira-DaSilva A. Meningiomas in lymphangioleiomyomatosis. JAMA 2001; 286: 1879-1881.

2. Franz DN. Meningiomas in women with lymphangioleiomyomatosis. JAMA 2002; 287: 1397-1398.

3. Longstreth WT Jr, Dennis LK, McGuire VM, Drangsholt
MT, Koepsell TD. Epidemiology of intracranial meningioma. Cancer 1993; 72: 639-648.

4. Jhawar BS, Fuchs CS, Colditz GA, Stampfer MJ. Sex steroid hormone exposures and risk for meningioma. $J$ Neurosurg 2003; 99: 848-853.

5. Hsu DW, Efird JT, Hedley-Whyte ET. Progesterone and estrogen receptors in meningiomas: prognostic considerations. J Neurosurg 1997; 86: 113-120.

6. Cai DX, James CD, Scheithauer BW, Couch FJ, Perry A. PS6K amplification characterizes a small subset of anaplastic meningiomas. Am J Clin Pathol 2001; 115: 213-218.

7. Krymskaya VP. Tumour suppressors hamartin and tuberin: intracellular signalling. Cell Signal 2003; 15: 729-739.

8. Carsillo T, Astrinidis A, Henske EP. Mutations in the tuberous sclerosis complex gene TSC2 are a cause of sporadic pulmonary lymphangioleiomyomatosis. Proc Natl Acad Sci USA 2000; 97: 6085-6090.

\title{
Strategies to increase the lung donors' pool
}

\section{To the Editors:}

In a recent issue of the European Respiratory Journal, DE PERRot et al. [1] suggested various strategies in order to increase the number of lung donors. Among these strategies, the extension of the lung donors' selection criteria was discussed. We would like to stress some points in a subtype of marginal donors. Most of the transplant coordination centres are reluctant to consider donors who present with brain death after a toxic exposure.

Data available from the organ procurement organisations are scarce. Cumulative data recovered from January 1988 to March 2004 by the US Organ Procurement and Transplantation Network revealed that, among the 10,981 lung donors recorded within the interval, the mechanism of death was drug intoxication in only 92 cases $(<1 \%)$. Similarly, the experience published by Eurotransplant (Austria, Belgium, Germany, Luxemburg and The Netherlands) is extremely limited. In 1996, a total of 168 lung transplantations were performed. The cause of death was mentioned as suicide for 15 donors $(9 \%)$. As suicide may have also included deaths secondary to gunshots, hanging or drowning, the overall percentage of intoxicated donors appears to be very low in this report.

In our centre (Dept of Intensive Care, Cliniques St-Luc, Université catholique de Louvain, Brussels, Belgium), from 293 organ donors, 864 organs were procured between January 1989 and December 1997. In contrast to the previous data, 21 $(7 \%)$ of our patients had developed brain death after acute poisoning [2]. A large number of intoxicants were used: cyanide, carbon monoxide, tricyclic antidepressants, barbiturates, paracetamol, insulin, and methanol. The outcome of the recipients of various organs was excellent. Bipulmonary transplantation was possible from a donor who died from methanol poisoning [3]. In the rejected cases, the lungs were not harvested for reasons that were independent from a toxic origin.

It is our experience that poisoned donors are often discarded a priori from organ donation, for fear of transferring the poisoning to the recipient with resultant organ dysfunction. However, the lung is seldom the main target organ of acute poisoning, with the notable exception of paraquat. Lung donation should be possible after acute overdose with the most frequent pharmaceutical drugs, including psychotropes.

Although there are data suggesting tricyclic antidepressants (TCA) accumulation in the lungs of a limited number of healthy volunteers, these data should not be extrapolated to transplant patients without caution [4]. There are data suggesting the feasibility of liver transplant in patients who died of TCA overdose and in whom TCA accumulation in the liver was demonstrated [5]. Accordingly, we believe that TCA overdose per se should not preclude a lung transplant.

Whereas fatalities after carbon monoxide exposure remain common, few numbers of lung transplantations have been reported [6]. It seems important to identify the source of carbon monoxide poisoning. Whilst various pulmonary lesions have been described following smoke inhalation, pure carbon monoxide poisoning is unlikely to be associated with chemical smoke-inhalation injury to the lung and lower airways [7].

Deaths in young donors are now frequently observed among illicit substance abusers. Successful lung transplantation has been performed from a donor who died after methylenedioxymethamphetamine ("ecstasy") exposure [8]. From a toxicological point of view, there is no reason to exclude ecstasy-intoxicated donors, provided that the commonly accepted criteria for organ donation are fulfilled.

In contrast, methadone has been reported to accumulate not only in the kidneys, spleen and liver, but also in the lungs. This should be particularly true in patients under maintenance therapy with multiple dosing. Acute lung injury is a rare but possible complication of acute methadone overdose [9].

The issue of organ donation after chronic use of inhaled drugs is still controversial. The pulmonary complications of inhaled cocaine are characterised by lesions of the alveolar wall and of the pulmonary microcirculation [10-12]. Shortterm exposure to cocaine may enhance the production of interleukin-8, a potent polymorphonuclear chemoattractant and neutrophil-activating factor, associated with both acute and chronic lung injury [12]. These data clearly preclude lung donation in these cases.

Regular marijuana smoking can induce alterations in the structure and function of alveolar macrophages, and these patients' lungs are unsuitable for transplantation [13]. This 
restriction does not apply to the occasional marijuana smoker.

In conclusion, lung donation after fatal acute poisoning, although difficult, could be considered in selected cases of poisoning by pharmaceutical drugs that are not associated with lung injury and in selected cases of pure carbon monoxide intoxication. Oral ecstasy poisoning, as well as occasional marijuana smoking, do not appear to be an absolute contraindication.

\section{P. Hantson, X. Wittebole, A. Liolios}

Dept of Intensive Care, Cliniques St-Luc, Université catholique de Louvain, Brussels, Belgium.

\section{References}

1. de Perrot M, Weder W, Patterson GA, Keshavjee S. Strategies to increase limited donor resources. Eur Respir $J$ 2004; 23: 477-482.

2. Hantson P. Organ donation after fatal poisoning: an update with recent literature data. Adv Exp Med Biol 2004; 550: 207213.

3. Evrard P, Hantson P, Ferrant E, Vanormelingen P, Mahieu P. Successful double lung transplantation with a graft obtained from a methanol-poisoned donor. Chest 1999; 115: 1458-1459.

4. Suhara T, Sudo Y, Yoshida K, et al. Lung as reservoir for antidepressants in pharmacokinetic drug interactions. Lancet 1998; 351: 332-335.
5. Fattinger KE, Rentsch KM, Meier PJ, Dazzi H, Krahenbuhl S. Safety of liver donation after fatal intoxication with the tricyclic antidepressant trimipramine. Transplantation 1996; 62: $1259-1262$.

6. Luckraz H, Tsui SS, Parameshwar J, Wallwork J, Large SR. Improved outcome with organs from carbon monoxide poisoned donors for intrathoracic transplantation. Ann Thorac Surg 2001; 72: 709-713.

7. Hantson P, Butera R, Clemessy JL, Michel A, Baud FJ. Early complications and value of initial clinical and paraclinical observations in victims of smoke inhalation without burns. Chest 1997; 111: 671-675.

8. Caballero F, Lopez-Navidad A, Cotorruelo J, Txoperena G. Ecstasy-induced brain death and acute hepatocellular failure: multiorgan donor and liver transplantation. Transplantation 2002; 74: 532-537.

9. Wolff K. Characterization of methadone overdose: clinical considerations and the scientific evidence. Ther Drug Monitor 2002; 24: 457-470.

10. Baldwin GC, Choi R, Roth MD, et al. Evidence of chronic damage to the pulmonary microcirculation in habitual users of alkaloidal ("crack") cocaine. Chest 2002; 121: 1231-1238.

11. Shanti CM, Lucas CE. Cocaine and the critical care challenge. Crit Care Med 2003; 31: 1851-1859.

12. Baldwin GC, Buckley DM, Roth MD, Kleerup EC, Tashkin DP. Acute activation of circulating polymorphonuclear neutrophils following in vivo administration of cocaine. A potential etiology for pulmonary injury. Chest 1997; 111: 698-705.

13. Tashkin DP. Airway effects of marijuana, cocaine and other inhaled illicit drugs. Curr Opinion Pulm Med 2001; 7: 43-61.

DOI: $10.1183 / 09031936.04 .00069704$

\section{End points for pulmonary arterial hypertension: a way backward}

\section{To the Editors:}

In the June 2004 issue of the European Respiratory Journal, PEACOCK et al. [1] recognised the need for end points, other than the assessment of functional capacity with the $6 \mathrm{~min}$ walking test, in pulmonary arterial hypertension (PAH) clinical trials. In their looking forward, the authors did not mention any role of the diffusing lung capacity for carbon monoxide $(D \mathrm{~L}, \mathrm{CO})$ test, which was originally devised in 1909-1915 [2]. However, as recently reviewed [2, 3], the measurement of lung gas transfer for $\mathrm{CO}(T \mathrm{~L}, \mathrm{CO})$ holds some premise into the evaluation of patients with PAH. In daily clinical practice, $T \mathrm{~L}, \mathrm{CO}$ is derived from the product of constant rate of alveolar to blood $\mathrm{CO}$ uptake and the accessible alveolar volume, which is usually preserved in $\mathrm{PAH}$; the examination of these two components allows exploration of the pathophysiological mechanism of $T \mathrm{~L}, \mathrm{CO}$ decrease at any time, due to pulmonary vascular abnormalities. Furthermore, the physiology of $\mathrm{CO}$ transfer is governed by the Roughton-Forster equation [4], partitioning the resistances to $\mathrm{CO}$ into membrane and red cell contributions, the latter accounting with appropriate calculations for $70-80 \%$ of total resistance [3]. Moreover, the $D \mathrm{~L}$ for $\mathrm{CO}$ or another suitable gas with greater haemoglobin affinity, such as nitric oxide, could be assessed at rest and during exercise, in combination with noninvasive measurement of cardiac output, providing sensitive indicators of the diffusive oxygen transport effectiveness, and structural alteration of the alveolar-capillary barrier [5, 6]. Therefore, it seems logical to assume abnormalities in $D \mathrm{~L}$ recruitment (or $D \mathrm{~L} /$ cardiac output ratio) occurring in PAH before chronic cardiac consequences would be detected during echocardiography. Accordingly, $D \mathrm{~L}, \mathrm{CO}$ decrease at rest is present in $80 \%$ of $\mathrm{PAH}$ patients [7], and it is significantly related to the main cardiopulmonary exercise test parameters of aerobic function [8], which, in turn, are relevant to the prognosis of PAH [9].

In conclusion, following the authors' suggestions, we believe that diffusing lung capacity tests, combined in parallel with other markers, should receive consideration for as broader an application as possible for markers of pulmonary arterial hypertension. Hopefully, a view backward may widen the way forward.

M. Sofia*, M. Maniscalco*, P. Carratù ${ }^{\#}$ O. Resta $*$ Dept of Respiratory Disease, University Federico II, Naples, and ${ }^{\#}$ Dept of Respiratory Disease, University of Bari, Bari, Italy.

\section{References}

1. Peacock A, Naeije R, Galie N, Reeves JT. End points in pulmonary arterial hypertension: the way forward. Eur Respir J 2004; 23: 947-953.

2. Hughes JMB, Bates DV. Historical review: the carbon 